\title{
Botanicals and Dietary Supplements in Diabetic Peripheral Neuropathy
}

\author{
Kathleen M. Halat, and Cathi E. Denneby, PharmD
}

Background: Many persons use botanicals and dietary supplements for chronic conditions that do not respond to traditional Western medications. Tricyclic antidepressants, a common treatment option for diabetic neuropathy, can have many side effects and are a poor choice in certain populations (eg, the elderly). As such, patients might turn to botanicals and dietary supplements, not realizing that these products are not well regulated.

Methods: This article reviews botanicals and dietary supplements that have been involved in randomized controlled trials (RCTs) for diabetic neuropathy. We searched MEDLINE for English-language literature dating from 1966 to April 2001 using the following subject headings: (1) diabetes and botanical, herb, and supplement, (2) neuropathy and botanical, herb, and supplement, and (3) diabetic neuropathy and botanical, herb, and supplement.

Results: Our search found agents that might improve symptoms of neuropathy (eg, evening primrose oil, alpha-lipoic acid, capsaicin) without affecting glucose control. Botanicals and dietary supplements involved in only one RCT or associated with little clinical benefit were reviewed in brief.

Conclusions: Evening primrose oil, alpha-lipoic acid, and capsaicin have received the greatest attention for their use in diabetic neuropathy, but further studies are needed to confirm their efficacy. Patients using these products need to be informed of potential drug interactions and side effects. ( $\mathrm{J}$ Am Board Fam Pract 2003;16:47-57.)

Peripheral neuropathy is a complication of both insulin dependent (type 1) and non-insulin-dependent (type 2) diabetes mellitus. It is characterized by a progressive loss of nerve fibers that predisposes the patient to painful or insensitive extremities, neuropathic ulceration, and amputation. Affected nerve functions include reduced nerve conduction velocity, decreased temperature sensation, decreased tendon reflex response, and a decreased ability to detect vibration and touch.

Long-term elevation of plasma glucose levels has been established as the definitive cause for diabetic peripheral neuropathy. ${ }^{1}$ With time, elevated plasma and nerve glucose levels contribute to nerve degeneration by a number of proposed mechanisms. These mechanisms include metabolic

Submitted, revised, 22 May 2002.

From the California College of Podiatric Medicine $(\mathrm{KMH})$, and the Department of Clinical Pharmacy (CED), University of California-San Francisco, San Francisco, Calif. Address reprint requests to Cathi Dennehy, PharmD, Department of Clinical Pharmacy, University of California, San Francisco, 521 Parnassus Ave, San Francisco, CA 94143-0622. changes, such as increased polyol pathway flux, increased formation of oxygen free radicals, and the formation of advanced glycosylation end products. $^{2}$ Reduced nerve perfusion and decreased production of prostaglandin vasodilators has also been proposed as contributing factors. ${ }^{3,4}$ Although tight glycemic control is the best way to avoid developing neuropathy, not all patients achieve this goal.

In 1994, the Dietary Supplement Health and Education Act, defined a dietary supplement as a vitamin, mineral, herb or other botanical, amino acid, or substance, such as a coenzyme, organ tissue, glandular, or metabolite. ${ }^{5}$ This article will review some of the botanicals and dietary supplements that might relieve symptoms associated with diabetic neuropathy but do not affect blood glucose control. Currently, these botanicals and supplements for neuropathy are being advertised to patients through various media and over the Internet. The purpose of this article is to review the scientific evidence for products that might benefit neuropathy or its pathologic features, rather than to recommend a particular product. 


\section{Methods}

We searched MEDLINE for English-language literature dating from 1966 to April 2001 using the following subject headings: (1) diabetes and botanical, herb, and supplement; (2) neuropathy and botanical, herb, and supplement; and (3) diabetic neuropathy and botanical, herb, and supplement. The bibliographies of pertinent articles and reviews on diabetic neuropathy that discussed alternative therapies were searched to find additional references. Randomized controlled trials (RCTs) conducted in humans and involving an herb, botanical, or supplement for diabetic neuropathy were included. Once a product was found, a separate MEDLINE search was performed using the name of that supplement to find additional RCTs.

Dietary supplements and botanicals having more than one RCT for diabetic neuropathy and reporting some favorable outcome were reviewed more extensively. These products included evening primrose oil, alpha-lipoic acid, and capsaicin. Dietary supplements and botanicals having only one RCT or associated with little clinical benefit were reviewed in brief. These products included acetylL-carnitine, pyridoxine (vitamin $\mathrm{B}_{6}$ ), vitamin $\mathrm{E}$, and St. John's wort.

\section{Evening Primrose Oil History}

Evening primrose oil is extracted from the seeds of Oenothera biennis. Evening primrose oil is a rich source of omega-6 essential fatty acids, primarily gamma-linolenic acid (GLA) and linoleic acid, both essential components of myelin and the neuronal cell membrane. Commercial preparations of evening primrose oil are typically standardized to $8 \%$ GLA and $72 \%$ linoleic acid. ${ }^{6}$

\section{Pharmacology}

Linoleic acid forms GLA by means of an enzymatic reaction involving $\Delta$-6-desaturase (Figure 1). GLA forms di-homo-gamma-linolenic acid (DGLA), which can be converted to prostaglandin $\mathrm{E}_{1}\left(\mathrm{PGE}_{1}\right)$ or to arachidonic acid byproducts (eg, series 2 prostaglandins $\left[\mathrm{PGE}_{2}\right]$, leukotrienes, and thromboxane). $\mathrm{PGE}_{1}$ is preferentially formed, however, because the conversion from DGLA to arachidonic acid is slower. ${ }^{7} \mathrm{PGE}_{1}$ has anti-inflammatory, antiplatelet, and vasodilating properties. $\mathrm{PGE}_{2}$, leuko- trienes, and thromboxane tend to promote inflammation, vasoconstriction, and platelet aggregation.

The enzymatic activity of $\Delta$-6-desaturase, which is compromised in patients with type 1 and type 2 diabetes mellitus, can decrease the production of $\mathrm{PGE}_{1} \cdot{ }^{8}$ Decreased production of $\mathrm{PGE}_{1}$ has been proposed to enhance the formation of $\mathrm{PGE}_{2}$ and thromboxane. ${ }^{9}$ As a result, levels of $\mathrm{PGE}_{1}$ are decreased, and levels of $\mathrm{PGE}_{2}$ and thromboxane are increased in patients with diabetes. ${ }^{10}$

Supplementing the diet with GLA has been shown to augment the production of $\mathrm{PGE}_{1}$ by bypassing the blocked enzymatic step. ${ }^{11,12}$ Supplementation with products rich in linoleic acid (eg, corn oil) is unlikely to be beneficial, as this action precedes the blocked step. ${ }^{13}$ Levels of $\mathrm{PGE}_{2}$, leukotrienes, and thromboxane are not increased in the presence of GLA. Although the exact mechanism is unclear, feedback inhibition from increased $\mathrm{PGE}_{1}$ synthesis might be responsible. ${ }^{?}$

\section{Clinical Studies}

Because GLA is an essential component of the neuronal membrane and has been shown to increase the production of $\mathrm{PGE}_{1}$, dietary supplementation with products rich in GLA (eg, evening primrose oil) has been suggested., ${ }^{914}$ Three RCTs have examined the effect of GLA in diabetic neuropathy; results from all three trials are detailed in Table 1. The first randomized, double-blind placebo-controlled study involved 22 patients with type 1 and type 2 diabetes mellitus and mild distal diabetic neuropathy for a mean of 3 years. ${ }^{15}$ Patients received $360 \mathrm{mg} / \mathrm{d}$ of GLA or an indistinguishable placebo for 6 months. Patients receiving GLA had statistically significant improvements in 6 of 6 nerve function measurements, wrist and ankle heat threshold values, and overall symptom scores. Glycohemoglobin $\left(\mathrm{HbA}_{1 \mathrm{C}}\right)$ was not significantly different between treatment groups, indicating that GLA had no effect on glucose control. Side effects were similar for patients receiving evening primrose oil and placebo.

The second trial was a larger randomized, double-blind placebo-controlled study involving 111 patients with type 1 and type 2 diabetes and mild or moderate neuropathy, 84 of whom completed the study. ${ }^{16}$ Patients with severe neuropathy were excluded. Patients received either a placebo (liquid paraffin) or $480 \mathrm{mg} / \mathrm{d}$ of GLA for 1 year. At 1 year, patients who received GLA had a statisti- 


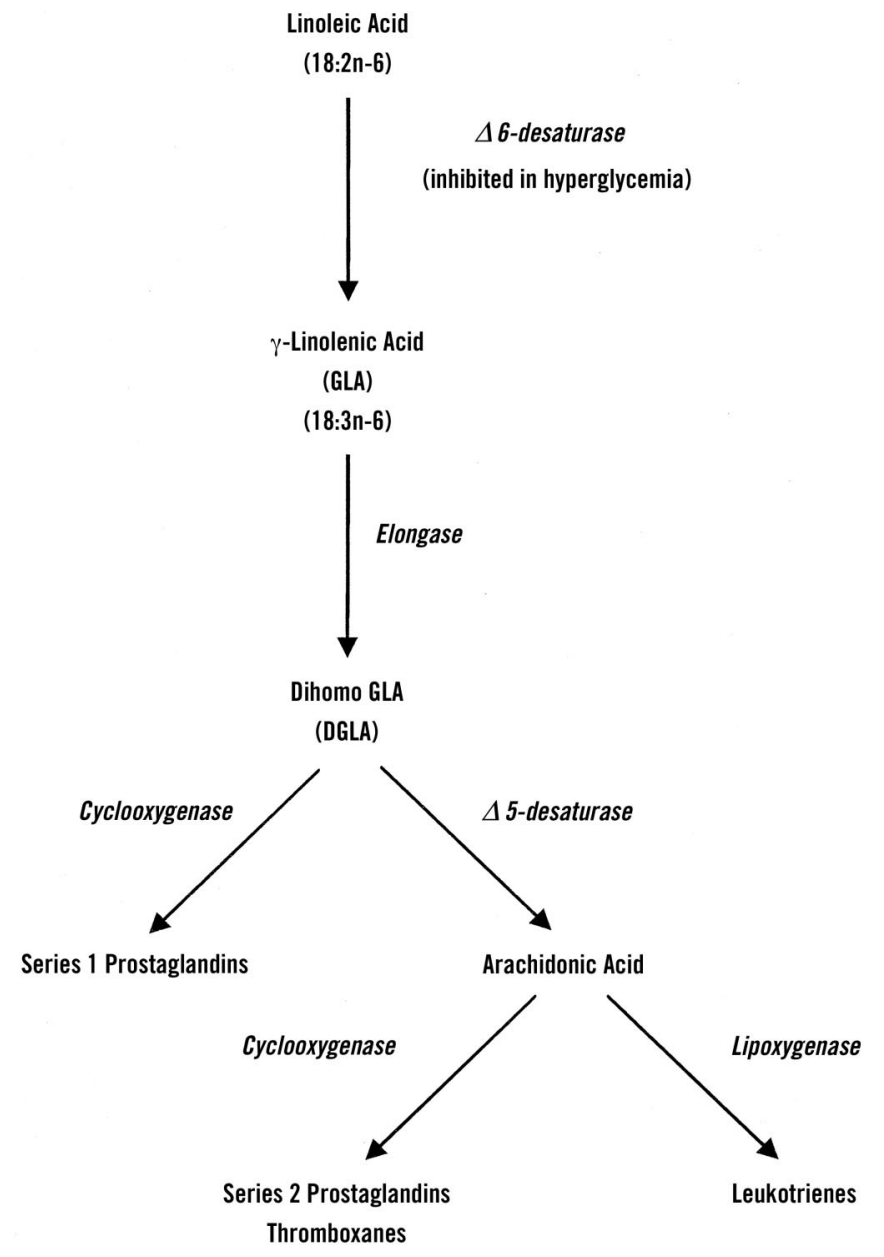

Figure 1. Production of series 1 and 2 prostaglandins from linoleic acid.

cally significant increase in 13 of 16 neural function measurements compared with placebo. Sex, age, and type of diabetes had no effect on the results. Side effects were similar in both groups. Improvements were significantly greater in patients with glycohemoglobin values of less than $10 \%$, defined as relatively well-controlled diabetes in this study, as compared with those with glycohemoglobin values of $10 \%$ or greater. Interestingly, the definition of relatively well-controlled diabetes used in this trial exceeds the current standard of $\mathrm{HbA}_{1 \mathrm{C}}<7 \%$ set by the American Diabetic Association (ADA). ${ }^{18}$

Results from the third trial examined vibratory perception threshold, a measurement different from those of previous trials. ${ }^{17}$ This randomized, double-blind, placebo-controlled study examined 51 patients with type 1 and type 2 diabetes and autonomic peripheral neuropathy who received $480 \mathrm{mg}$ or GLA a day or placebo for 1 year. At the study endpoint, patients receiving evening prim- rose oil showed no improvements in vibratory perception threshold compared with placebo.

\section{Adverse Effects, Cautions, and Drug Interactions}

In clinical trials, the side effect profile for evening primrose oil was generally mild and similar to placebo. Evening primrose oil might interact with certain prescription and nonprescription medications, however. By decreasing the formation of thromboxane and increasing the formation $\mathrm{PGE}_{1}$, evening primrose oil can inhibit platelet aggregation. Patients taking antiplatelet or anticoagulant medications should use evening primrose oil cautiously or not at all. Theoretically, the effects of evening primrose oil could also be diminished by nonsteroidal anti-inflammatory medications that block prostaglandin formation. There have been case reports of seizures in patients taking evening primrose oil for schizophrenia ${ }^{19}$ and in a patient using a combination evening primrose oil, black cohosh, and chasteberry product 
Table 1. Clinical Trials of Evening Primrose Oil and Diabetic Neuropathy.

\begin{tabular}{|c|c|c|c|c|c|}
\hline Trial & Design & $\begin{array}{l}\text { Number } \\
\text { R/C }\end{array}$ & Dose & $\begin{array}{l}\text { Duration } \\
\text { (mo) }\end{array}$ & Outcome* \\
\hline $\begin{array}{l}\text { Jamal \& Carmichael, }{ }^{15} \\
\end{array}$ & $\mathrm{R}, \mathrm{DB}, \mathrm{PL}$ & $22 / 22$ & $360 \mathrm{mg} \mathrm{qd}$ & 6 & $\begin{array}{l}\text { Significant improvement } \\
\text { Symptom scores }(-2.1 \text { vs } 0.9) \\
\text { Median MCV }(1.4 \text { vs }-1.4) \\
\text { Peroneal MCV }(1.9 \text { vs }-0.1) \\
\text { Median CMAP }(1.0 \text { vs }-0.7) \\
\text { Peroneal CMAP }(0.7 \text { vs }-0.3) \\
\text { Median }(1.8 \text { vs }-1.7) \\
\text { Sural SNAP }(0.4 \text { vs }-1.5) \\
\text { Ankle HT }\left({ }^{\circ} \mathrm{C}\right)(-2.3 \text { vs } 0.5) \\
\text { Wrist HT }\left({ }^{\circ} \mathrm{C}\right)(-0.5 \text { vs } 0.02) \\
\text { Not significant } \\
\text { Sign scores } \\
\text { Ankle, wrist CT }\left({ }^{\circ} \mathrm{C}\right)\end{array}$ \\
\hline Keen et al, ${ }^{16} 1993$ & R,DB,PL & $111 / 84$ & $480 \mathrm{mg} \mathrm{qd}$ & 12 & $\begin{array}{l}\text { Significant improvements } \\
\text { Median MCV }(2.4 \text { vs }-2.1) \\
\text { Peroneal MCV }(2.2 \text { vs }-1.9) \\
\text { Extensor digitorum brevis CMAP }(1.2 \text { vs }-0.6) \\
\text { Thenar CMAP }(1.4 \text { vs }-1.1) \\
\text { Median SNAP }(2.4 \text { vs }-1.3) \\
\text { Sural SNAP }(1.7 \text { vs }-1.0) \\
\text { Wrist HT }\left({ }^{\circ} \mathrm{C}\right)(0.8 \text { vs }-0.4) \\
\text { Wrist CT }\left({ }^{\circ} \mathrm{C}\right)(0.8 \text { vs }-0.3) \\
\text { Arm tendon reflex }(2.9 \text { vs }-12.0) \\
\text { Leg tendon reflex }(17.7 \text { vs } 0.5) \\
\text { Arm sensation }(6.9 \text { vs }-7.3) \\
\text { Leg sensation }(15.0 \text { vs }-8.4) \\
\text { Arm muscle strength }(4.9 \text { vs }-7.4) \\
\text { Not significant } \\
\text { Ankle HT and CT }\left({ }^{\circ} \mathrm{C}\right) \\
\text { Leg muscle strength }\end{array}$ \\
\hline Purewal et al, ${ }^{17} 1997$ & $\mathrm{R}, \mathrm{DB}, \mathrm{PL}$ & $51 / 51$ & $480 \mathrm{mg} \mathrm{qd}$ & 12 & $\begin{array}{l}\text { Not significant } \\
\text { Vibratory threshold at hallux }\end{array}$ \\
\hline
\end{tabular}

$\mathrm{R}=$ randomized, $\mathrm{DB}=$ double-blind, $\mathrm{PL}=$ placebo-controlled, $\mathrm{C}=$ number of patients completing trial, $\mathrm{MCV}=$ median conduction velocity, CMAP = compound muscle action potential, SNAP $=$ sensory nerve action potential, HT $=$ heat threshold, $\mathrm{CT}=$ cold threshold.

*Numbers in parenthesis indicate significant difference compared with placebo in favor of evening primrose oil.

for premenstrual symptoms. ${ }^{20}$ Product analysis, however, was not performed, so the causative agent could not be confirmed. Caution is advised for patients with preexisting seizure disorders.

\section{Formulation and Dosage}

In trials reporting positive results, a treatment duration of 6 to 12 months was generally required. Efamol, the most common formulation used, is available in the United States as $500-\mathrm{mg}$ capsules. The recommended dose of evening primrose oil is 8 to $12,500-\mathrm{mg}$ capsules each day. Each capsule has $40 \mathrm{mg}$ of GLA, so a dose of 360 to $480 \mathrm{mg}$ of GLA requires 9 to 12 capsules. Given this large quantity of capsules, patient compliance could be a problem. Furthermore, the oil content of the recommended dose could potentially contribute to weight gain, an already undesirable effect in overweight diabetics.

\section{Clinical Recommendation}

At the present time, the body of knowledge concerning evening primrose oil and diabetic neuropathy is limited and inconclusive. Beneficial results from two clinical trials and a mild side-effect profile, however, suggest that evening primrose oil might be useful in cases of mild diabetic neuropathy. It might also be useful as an add-on therapy for patients with mild to moderate neuropathy who achieve only partial relief from prescription drug therapy. In such cases, patients need to be educated about proper dosage, potential drug interactions, and side effects.

\section{Alpha-Lipoic Acid History}

Alpha-lipoic acid, also known as thioctic acid, is approved for clinical use in the management of diabetic neuropathy in Germany. ${ }^{21}$ Treatment with alpha- 
Table 2. Clinical Trials of Alpha-Lipoic Acid (ALA) and Diabetic Neuropathy.

\begin{tabular}{|c|c|c|c|c|c|}
\hline Trial & Design & $\begin{array}{l}\text { Number } \\
\text { R/C }\end{array}$ & Dose & Duration & Outcome* \\
\hline$\underset{1995^{24}}{\text { Ziegler et }}$ & R,DB,PL & $328 / 260$ & $\begin{array}{l}\text { 100, } 600 \text {, or } 1,200 \mathrm{mg} \text { qd } \\
\text { parenteral ALA }\end{array}$ & $3 \mathrm{wk}$ & $\begin{array}{l}\text { Significant improvements } \\
\text { HPAL-600/1,200 } \\
(-1.4 /-1.2 \text { vs }-0.5) \\
\text { HPAL } \\
\text { NDS- } 1,200(-1.8 \text { vs }-1.0) \\
\text { PGE-600 }(76 \% \text { vs } 46 \%) \\
\text { Not significant } \\
\text { HPAL-100; NDS-100/600 } \\
\text { PGE- } 100 / 1,200\end{array}$ \\
\hline $\begin{array}{l}\text { Reljanovic et al, }{ }^{26} \\
1999\end{array}$ & R,DB,PL & $299 / 169 / 65^{\dagger}$ & $\begin{array}{l}600 \text { or } 1,200 \mathrm{mg} \text { qd } \\
\quad \text { oral ALA }\end{array}$ & $2 y$ & $\begin{array}{l}\text { Significant improvements } \\
\text { Sural SNCV-600/1,200 } \\
(3.0 / 3.8 \text { vs }-0.1) \\
\text { Sural SNAP-600 (0.3 vs -0.7) } \\
\text { Tibial MNCV-1,200 } \\
\quad(1.2 \text { vs }-1.5) \\
\text { Not significant } \\
\text { Sural SNAP-1,200; tibial } \\
\text { MNCV-600 } \\
\text { Tibial MNDL-600/1,200; } \\
\text { NDS-600/1,200 }\end{array}$ \\
\hline $\begin{array}{l}\text { Ziegler et al, }{ }^{27} \\
1999^{24}\end{array}$ & R,DB,PL & $503 / 377$ & $\begin{array}{l}\text { 1. } 600 \mathrm{mg} \text { qd parenteral ALA } \\
(3 \mathrm{wk}) \text { then } 1,800 \mathrm{mg} \text { qd } \\
\text { oral ALA (6 mo) OR } \\
\text { 2. } 600 \mathrm{mg} \text { qd parenteral ALA } \\
(3 \mathrm{wk}) \text { then oral placebo } \\
(6 \mathrm{mo}) \text { OR } \\
\text { 3. Parenteral placebo }(3 \mathrm{wk}) \\
\text { then oral placebo }(6 \mathrm{mo})\end{array}$ & $6 \mathrm{mo}$ & $\begin{array}{l}\text { Significant improvements } \\
\text { NIS-3 wk }(-4.3 \text { vs }-3.5) \\
\text { NIS-LL-3 wk }(-3.3 \text { vs }-2.8) \\
\text { Not significant } \\
\text { TSS-3 wk/6 mo } \\
\text { NIS }-6 \text { mo; NIS-LL_6 mo }\end{array}$ \\
\hline $\begin{array}{l}\text { Ruhnau et al, }_{1999}{ }^{28} \\
\end{array}$ & R,DB,PL & $24 / 22$ & $1,800 \mathrm{mg}$ qd oral ALA & $3 \mathrm{wk}$ & $\begin{array}{l}\text { Significant improvements } \\
\text { TSS }(-3.8 \text { vs }-1.9) \\
\text { NDS }(-0.3 \text { vs } 0.2) \\
\text { Not significant } \\
\text { HPAL }\end{array}$ \\
\hline
\end{tabular}

$\mathrm{R}=$ randomized, $\mathrm{DB}=$ double-blind, $\mathrm{PL}=$ placebo-controlled, $\mathrm{C}=$ number of patients completing trial, HPAL = Hamburg pain adjective list, NDS = neuropathy disability score, PGE = physician's global evaluation based on a rating scale of change in pain severity, SNCV = sensory nerve conduction velocity, SNAP = sensory nerve action potential, $\mathrm{MNCV}=$ motor nerve conduction velocity, MNDL = motor nerve distal latency, NIS = neuropathy impairment score, NIS-LL = neuropathy impairment score-lower limb, TSS $=$ total symptom score.

*Numbers in parenthesis indicate significant difference compared with placebo in favor of ALA.

${ }^{\dagger}$ Although 169 patients completed the trial, data from only 65 patients were used because of problems with data collection.

lipoic acid improves nerve blood flow and distal nerve conduction and increases endoneurial glucose uptake and energy metabolism in animals. ${ }^{22,23}$ Alpha-lipoic acid has also been used to reduce oxidative damage associated with mushroom poisoning, radiation, and alcoholic hepatitis. $^{21}$

\section{Pharmacology}

Alpha-lipoic acid is an endogenous, sulfur-containing, free radical scavenger found in mitochondria. Free radicals can reduce nitric-oxide-mediated vasodilation and damage to the vascular endothelium. ${ }^{2}$ Alphalipoic acid also recycles other antioxidants, such as vitamins $\mathrm{E}$ and $\mathrm{C}$, but can chelate with transition metals, such as iron and copper. Because it is both fatand water-soluble, alpha-lipoic acid reduces oxidation throughout the body. ${ }^{21}$

\section{Clinical Trials}

A systematic review of 15 trials concluded that short-term treatment with parenteral alpha-lipoic acid, $600 \mathrm{mg} / \mathrm{d}$, reduced neuropathic symptoms and deficits. ${ }^{24}$ These conclusions were primarily based on the results of four randomized, doubleblind, placebo-controlled studies entitled ALADIN (Alpha Lipoic Acid in Diabetic Neuropathy), ALADIN II, ALADIN III, and ORPIL (Oral Pilot), the results of which are detailed in Table 2. Problems with sample size, study design, and the way in which neuropathic symptoms were scored made results from the previous 10 trials inconclusive. An additional trial that assessed cardiac autonomic neuropathy will not be discussed.

In the ALADIN study, 328 patients with type 2 diabetes mellitus and symptomatic peripheral neu- 
ropathy were randomly assigned to 100,600 , or $1,200 \mathrm{mg} / \mathrm{d}$ of parenteral alpha-lipoic acid or placebo. $^{25}$ At 3 weeks, of the 260 patients that completed the study, those receiving the 600 and 1,200 $\mathrm{mg} / \mathrm{d}$ doses of alpha-lipoic acid had statistically significant improvements in pain, paresthesias, and numbness compared with placebo. Improvements at the $1,200 \mathrm{mg} / \mathrm{d}$ dose were greater, but this group also reported more adverse effects (eg, gastrointestinal upset and headache). Glycohemoglobin levels were similar among treatment groups at 3 weeks, indicating that alpha-lipoic acid did not affect glucose control.

The ALADIN II study examined the effects of oral alpha-lipoic acid, 600 or $1,200 \mathrm{mg} / \mathrm{d}$, in 65 patients with type 1 and type 2 diabetes and symptomatic polyneuropathy. ${ }^{26}$ At 2 years, both doses of alpha-lipoic acid showed a statistically significant increase in nerve conduction velocity compared with placebo. Severity of symptoms was not improved, however, based on the Neuropathy Disability Score. The Neuropathy Disability Score measures ankle reflexes, vibration, pinprick, and temperature sensation at the great toe and was developed to screen large populations of patients in epidemiologic studies. ${ }^{29}$ As a result, the sample size in the ALADIN II study might have been too small to detect significant changes in the Neuropathy Disability Score. Glycohemoglobin levels were similar between groups at the study endpoint.

ALADIN III examined the effects of short-term treatment with parenteral alpha-lipoic acid followed by extended treatment with oral alpha-lipoic acid. ${ }^{27}$ In this multicenter trial, 503 patients with type 2 diabetes and symptomatic peripheral neuropathy were placed in one of three treatment groups: (1) $600 \mathrm{mg} / \mathrm{d}$ parenteral alpha-lipoic acid for 3 weeks, then $1,800 \mathrm{mg} / \mathrm{d}$ of oral alpha-lipoic acid for 6 months; (2) $600 \mathrm{mg} / \mathrm{d}$ parenteral alphalipoic acid for 3 weeks, then an indistinguishable oral placebo for 6 months; or (3) parenteral placebo for 3 weeks, then oral placebo for 3 months. Neuropathic deficits were significantly reduced in patients receiving parenteral alpha-lipoic acid at 3 weeks. After 6 months of treatment with oral alphalipoic acid, a decrease in neuropathy impairment scores was observed; however, this difference was not significant. At the study endpoint, no significant differences were detected in glycohemoglobin levels or adverse side effects between the treatment groups.
Contrary to the results from ALADIN III, the ORPIL study found that oral administration of 1,800 $\mathrm{mg} / \mathrm{d}$ of alpha-lipoic acid reduced neuropathic deficits and symptoms in patients with type 2 diabetes and symptomatic polyneuropathy during a 3-week period. ${ }^{28}$ The sample size in this trial, however, was substantially smaller; only 22 patients completed the trial.

Two additional studies entitled NATHAN (Neurological Assessment of Thioctic Acid in Neuropathy) I and II are currently underway. ${ }^{24}$ NATHAN I is a randomized, 4-year, double-blind, placebo-controlled investigation to examine the effect of oral alpha-lipoic acid on diabetic polyneuropathy. NATHAN II, like the ALADIN studies, examines the effect of short-term (3-week) parenteral alpha-lipoic acid. Both studies are likely to provide further insight into questions regarding formulation, treatment duration, and clinical efficacy.

\section{Adverse Effects, Cautions, and Drug Interactions}

Clinical and postmarketing surveillance studies have indicated that alpha-lipoic acid has a favorable side effect profile. ${ }^{24}$ Adverse effects are mild and include headache, skin rash, stomach upset at high doses (>600 mg/d) and possible hypoglycemia. ${ }^{21,26}$ Patients and physicians need to be aware that alpha-lipoic acid is a chelating agent and might cause mineral shortages in the body. As a result, iron levels should be monitored in patients taking alphalipoic acid. In addition, a vitamin B supplement should be taken if alpha-lipoic acid is given to patients who are thiamine-deficient (eg, alcoholics). Patients taking other medications that chelate with alpha-lipoic acid (eg, antacids) should space the dosing of these products by at least 2 hours.

\section{Formulation and Dosing}

In clinical trials, symptomatic improvements were more likely to be observed after short-term parenteral use than after long-term use of oral alphalipoic acid. It is not available in the United States as a parenteral formulation, but tablet strengths ranging from 30 to $100 \mathrm{mg}$ are available. Some clinical trials report significant improvements in nerve conduction velocity with oral doses of 600 to 1,200 $\mathrm{mg} / \mathrm{d}$ for 2 years. ${ }^{26}$ Symptom improvement was also observed using $1,800 \mathrm{mg} / \mathrm{d}$ for 3 weeks. ${ }^{28}$ The optimal dose for oral dosing is currently unknown, but a minimum treatment duration of 3 weeks is likely required. 


\section{Clinical Recommendation}

As more research on the long-term benefits of alpha-lipoic acid become available, statements concerning the long-term safety and clinical effectiveness can be made. At this time, because alpha-lipoic acid has a limited side effect profile and is already approved in Germany for diabetic neuropathy, it should be considered as a treatment option for diabetic patients with mild to moderate neuropathy. In such cases, patients should be educated about the potential side effects and vitamin and mineral deficiencies associated with alpha-lipoic acid use.

\section{Capsaicin \\ History}

Capsaicin, an ingredient in chili pepper, has been used for centuries both orally for dyspepsia and topically as a counterirritant. ${ }^{30}$ Today, capsaicin is most often used for its analgesic properties for a variety of disorders, including osteoarthritis, postmastectomy pain, cluster headache, psoriasis, postherpectic neuralgia, and diabetic neuropathy. ${ }^{30,31}$ Unlike many other botanical-based products, capsaicin is regulated as an over-the-counter product by the Food and Drug Administration and therefore meets manufacturing, safety, and clinical efficacy standards for over-the-counter products.

\section{Pharmacology}

Diabetic sensory neuropathy involves both large and small sensory fibers. While large-fiber involvement is often painless, small-fiber loss can manifest as symptoms of shooting, burning, or sharp pain and aching. ${ }^{32}$ Capsaicin directly affects sensory fibers, especially C-fibers. ${ }^{31}$ The capsaicin receptor that is located only on small, slow-conducting, unmyelinated C-fibers regulates calcium flux. ${ }^{31}$ Initial application of capsaicin stimulates these fibers and depletes endogenous neurotransmitter stores associated with pain transmission, such as substance $\mathrm{P}$, vasoactive intestinal peptide, cholecystokinin, and somatostatin. ${ }^{33}$ The result can be a burning sensation within the first few weeks of use. Successive application, however, results in a dose-dependent degeneration and desensitization of afferent fibers, blocking further action potential conduction. ${ }^{31}$ By maintaining afferent sensations for touch, temperature, and vibration and by blocking those for pain, patients with neuropathy who use capsaicin can continue to monitor for signs of possible foot ulceration. $^{34}$

\section{Clinical Studies}

Only one trial has compared topical capsaicin to tricyclic antidepressants for diabetic neuropathy. ${ }^{35}$ This randomized, double-blind trial enrolled 250 patients with type 1 and type 2 diabetes mellitus and painful chronic neuropathy. Patients received topical capsaicin $0.075 \%$ four times a day and oral placebo or topical placebo and oral amitriptyline titrated up from $25 \mathrm{mg} / \mathrm{d}$ to a maximum of 125 $\mathrm{mg} / \mathrm{d}$ (mean dose not stated). Methyl nicotinate was used as the topical placebo for the first 2 weeks to simulate the burning associated with capsaicin. After 8 weeks, equivalent, statistically significant improvements in pain severity, pain relief, and activities of daily living were observed in both groups compared with baseline. The differences were not significantly different between groups, indicating an equivalent clinical response. Systemic adverse effects were significantly more frequent in patients receiving amitriptyline (eg, sedation, anticholinergic effects), while topical skin reactions were significantly more frequent in patients receiving capsaicin. The latter might have compromised blinding. In addition, given the lack of a topical and oral placebo arm, the magnitude of a placebo response is unknown.

Other randomized, double-blind trials have compared topical capsaicin $0.075 \%$ with topical placebo for 4 to 12 weeks in patients with diabetic neuropathy. ${ }^{32,36-39}$ These trials are described in detail in Table 3. All trials assessed pain based on three scales: the Physician's Global Evaluation scale (PGE), which rates patient's pain as completely gone $(+3)$, much better $(+2)$, better $(+1)$, no change $(0)$, worse $(-1)$, or much worse $(-2)$, a $100-\mathrm{mm}$ visual analog scale for severity (VAS-P), and a similar scale for relief (VAS-R). Four trials enrolled 22 to 277 patients with types 1 and 2 diabetes and moderate to severe neuropathy. ${ }^{32,36-38}$ Two reported significant improvements in all three outcome measures at 8 weeks, ${ }^{32,37}$ whereas two reported significant improvements in only one outcome measure at 4 to 8 weeks. ${ }^{36,38}$

In most trials, patients were more likely to experience burning after application with capsaicin (60\% to $63 \%$ ) compared with placebo (17\% to $20 \%$, which could have affected blinding. The largest trial also had a significantly higher dropout 
Table 3. Clinical Trials of Capsaicin and Diabetic Neuropathy.

\begin{tabular}{|c|c|c|c|c|c|}
\hline Trial & Design & $\begin{array}{l}\text { Number } \\
\text { R/C }\end{array}$ & Dose & Duration (wk) & Outcome* \\
\hline Chad et $\mathrm{al}^{36}{ }^{36} 1990$ & R,DB,PL & $58 / 46$ & $0.075 \%$ cap qid & 4 & $\begin{array}{l}\text { Significant improvements } \\
\text { VAS-R (71 vs 41\%) } \\
\text { Not significant } \\
\text { VAS-P } \\
\text { PGE }\end{array}$ \\
\hline Scheffler et al, ${ }^{32} 1991$ & R,DB,PL & $54 / 49$ & $0.075 \%$ cap qid & 8 & $\begin{array}{l}\text { Significant improvements } \\
\text { PGE (90 vs } 50 \% \text { ) } \\
\text { VAS-P (49 vs } 17 \% \text { ) } \\
\text { VAS-R (66 vs } 39 \%)\end{array}$ \\
\hline $\begin{array}{l}\text { Capsaicin Study Group, }{ }^{37} \\
1991\end{array}$ & R,DB,PL & $277 / 219$ & $0.075 \%$ cap qid & 8 & $\begin{array}{l}\text { Significant improvements } \\
\text { PGE (71 vs } 51 \% \text { ) } \\
\text { VAS-P (40 vs } 28 \%) \\
\text { VAS-R ( } 60 \text { vs } 45 \%)\end{array}$ \\
\hline Tandan et al, ${ }^{38} 1992$ & R,DB,PL & $22 / 20$ & $0.075 \%$ cap qid & 8 & $\begin{array}{l}\text { Significant improvements } \\
\text { PGE (60 vs 20\%) } \\
\text { Not significant } \\
\text { VAS-P } \\
\text { VAS-R }\end{array}$ \\
\hline Low et $\mathrm{al}^{39}{ }^{39} 1995^{+}$ & R,DB,PL & $40 / 39$ & $0.075 \%$ cap qid & 12 & $\begin{array}{l}\text { Not significant } \\
\text { PGE } \\
\text { VAS-P } \\
\text { VAS-R }\end{array}$ \\
\hline
\end{tabular}

Note: $\mathrm{R}=$ randomized, $\mathrm{DB}=$ double-blind, $\mathrm{PL}=$ placebo-controlled, $\mathrm{C}=$ number of patients completing trial, VAS-R $=$ visual analogue scale for pain relief, VAS-P = visual analogue scale for pain severity, PGE = physician's global evaluation based on a rating scale of change in pain severity.

*Numbers in parenthesis indicate significant difference in favor of capsaicin compared with placebo.

${ }^{\dagger}$ Only $12 \%$ of patients enrolled in this trial had diabetes.

rate for patients using capsaicin. ${ }^{37}$ When the results of this trial were analyzed again using an intentionto-treat analysis, all three outcome measures became insignificant. Meta-analysis of these four trials, however, still showed a significant benefit for capsaicin compared with placebo, with an odds ratio of 2.74 (95\% confidence interval $1.73-4.32){ }^{30}$ In a fifth trial, 40 patients with moderate distal neuropathy, of which 7 (12\%) had diabetes, experienced no improvement in any outcome measure at 12 weeks. ${ }^{39}$ This trial also used a methyl nicotinate placebo to simulate the initial burning sensation from capsaicin.

\section{Adverse Effects, Cautions, and Drug Interactions}

Capsaicin is commonly associated with a burning sensation at the site of application that lasts 2 to 14 days. This sensation might affect patient compliance, and patients should be advised to continue use, if the pain is tolerable, because up to 4 to 6 weeks can pass before benefits are appreciated. Application with gloves is recommended to avoid contact with the eyes and other mucous membranes. Patients with open wounds or broken skin should avoid contact with capsaicin in these areas. There are no drug-drug interactions reported for capsaicin.

\section{Formulation and Dosing}

Capsaicin is available without a prescription in two strengths, $0.025 \%$ and $0.075 \%$, but the higher strength has typically been used for diabetic neuropathy. It is important that both patients and health care providers know that capsaicin used on a daily, twice daily, or as-needed basis is likely ineffective. Clinical trials show that application must take place three to four times a day for improvement.

\section{Clinical Recommendation}

The clinical usefulness of capsaicin is not conclusive. It could be effective as monotherapy in cases of mild to moderate diabetic neuropathy. It might also be useful as an adjunctive agent in combination with prescription drug therapy. The appropriate dosing of capsaicin is essential for symptomatic improvement. Unfortunately, many patients and providers often prescribe this product at too low dosages. 


\section{Other Dietary Supplements}

A number of other dietary supplements have been promoted as treatments for diabetic neuropathy. These supplements include acetyl-L-carnitine, pyridoxine (vitamin $\mathrm{B}_{6}$ ), vitamin $\mathrm{E}$, and St. John's wort. In general, these products have been less well researched or have reported negative findings for diabetic neuropathy.

\section{Acetyl-L-carnitine}

Acetyl-L-carnitine, an endogenous substance similar in structure to acetylcholine, is involved in the uptake and oxidation of long-chain fatty acids in mitochondria. ${ }^{40}$ Low levels of acetyl-L-carnitine have been found in the sciatic nerve of diabetic rats, and acetyl-L-carnitine supplementation has been shown to improve nerve function. ${ }^{41-43}$ In humans, two studies have examined the effect of acetyl-Lcarnitine on diabetic neuropathy. The first RCT examined 20 patients with symptomatic neuropathy for a 15 -day period. ${ }^{40}$ Patients received either intramuscular acetyl-L-carnitine or placebo at 1,000 $\mathrm{mg} / \mathrm{d}$. At the end of the study, patients receiving acetyl-L-carnitine showed a significant decrease in neuropathic symptoms compared with placebo, but no change in vibratory perception threshold.

The second study was a much larger randomized, double-blind, placebo-controlled study that examined the effect of acetyl-L-carnitine administration on neuropathic symptoms and first foot ulceration. ${ }^{44}$ In this study, 1,035 patients with type 1 and 2 diabetes and peripheral neuropathy received $1,000 \mathrm{mg} / \mathrm{d}$ of oral acetyl-L-carnitine or placebo for 1 year. At the study endpoint, there were no significant differences in neurological parameters (vibratory perception threshold, muscle strength, reflexes, 10-g monofilament scores) or rate of first foot ulceration between treatment groups.

\section{Vitamin $B_{6}$}

Low levels of vitamin $\mathrm{B}_{6}$ have been reported in patients with diabetic neuropathy but not in diabetic patients without neuropathy. ${ }^{45}$ Deficiencies of vitamin $\mathrm{B}_{6}$ have also been linked to peripheral neuropathy in persons consuming isoniazid. ${ }^{46}$ As such, a number of studies have evaluated the effectiveness of vitamin $\mathrm{B}_{6}$ in diabetic neuropathy. One small-scale, 6-week trial, with an open-study design evaluated the effect of $25 \mathrm{mg}$ of oral vitamin $\mathrm{B}_{6}$ in
10 diabetic patients. ${ }^{47}$ Although this trial observed symptomatic improvement in all patients, three subsequent randomized, double-blind placebocontrolled studies found no benefit. ${ }^{48-50}$

\section{Vitamin E}

The effect of vitamin $\mathrm{E}$ on nerve function parameters was evaluated in a randomized, double-blind, placebo-controlled trial involving 21 patients with type 2 diabetes and mild-to-moderate neuropathy. ${ }^{51}$ Patients received 900 IU of vitamin E or placebo for 6 months. Although there were no changes in glycemic indices, both median and tibial motor nerve conduction velocity were significantly improved in the vitamin $\mathrm{E}$ group compared with placebo.

\section{St John's Wort}

St. John's wort has been proposed as an analgesic for painful diabetic neuropathy. Similar to the tricyclic antidepressants that are used in the management of neuropathy, St. John's wort might also have antidepressant qualities. One study examined the effect of St. John's wort on pain in patients with diabetic and nondiabetic neuropathy. ${ }^{52}$ In this double-blind study, 47 patients, 18 diabetic and 29 nondiabetic, randomly received $900 \mathrm{mg} / \mathrm{d}$ of oral St. John's wort or placebo for 5 weeks. They then crossed over to the other therapy for an additional 5 weeks. At the study endpoint, diabetic patients who received St. John's wort had a statistically significant reduction in lancinating (shooting) pain compared with placebo. There were no changes, however, in other measures of total pain score, constant pain, touch-evoked pain, or pain on pressure as compared with placebo.

\section{Clinical Recommendation}

Because of the lack of research on the effectiveness of acetyl-L-carnitine, vitamin $\mathrm{B}_{6}$, vitamin $\mathrm{E}$, and St. John's wort for the treatment of diabetic neuropathy, these supplements cannot be recommended at this time. Health care providers should direct patients toward those therapies that have been better researched or have shown positive outcomes in clinical trials.

\section{Conclusion}

Although adequate glucose control is a mainstay of treatment for diabetic neuropathy, other treat- 
ments may be used by patients if symptom relief is not adequate. The accessibility of botanical and dietary supplement products, as well as direct-toconsumer advertising, makes these choices attractive for many patients. All the botanicals and dietary supplements discussed in this review, with the exception of capsaicin, have shortcomings as a result of their regulation by the Dietary Supplement Health and Education Act. Specifically, there is no guarantee of efficacy, safety, or product content. Evening primrose oil, alpha-lipoic acid, and capsaicin have received the greatest attention for their use in diabetic neuropathy, but further studies are needed to confirm their efficacy.

\section{References}

1. The effect of intensive diabetes therapy on the development and progression of neuropathy. The Diabetes Control and Complications Trial Research Group. Ann Intern Med 1995;122:561-8.

2. Cameron NE, Cotter MA. Metabolic and vascular factors in the pathogenesis of diabetic neuropathy. Diabetes 1997;46(Suppl 2):S31-7.

3. McCarty MF. Nitric oxide deficiency, leukocyte activation, and resultant ischemia are crucial to the pathogenesis of diabetic retinopathy/neuropathypreventive potential of antioxidants, essential fatty acids, chromium, ginkgolides, and pentoxifylline. Med Hypotheses 1998;50:435-49.

4. Young MJ, Veves A, Walker MG, Boulton AJ. Correlations between nerve function and tissue oxygenation in diabetic patients: further clues to the aetiology of diabetic neuropathy? Diabetologia 1992;35: 1146-50.

5. Dietary supplement health and education act of 1994, P.L. 103-417. [103rd Cong, 2nd Sess, Jan 25, 1994.] Washington, DC: Congressional Research Service, Library of Congress, 1994.

6. Carter JP. Gamma-linolenic acid as a nutrient. Food Tech 1988;42(6):72-82.

7. Horrobin DF. The regulation of prostaglandin biosynthesis by the manipulation of essential fatty acid metabolism. Rev Pure Appl Pharmacol Sci 1983;4: 339-83.

8. Brenner RR. Nutritional and hormonal factors influencing desaturation of essential fatty acids. Progr Lipid Res 1982;20:41-8.

9. Horrobin DF. A new concept of lifestyle-related cardiovascular disease: the importance of interactions between cholesterol, essential fatty acids, prostaglandin E1 and thromboxane A2. Med Hypotheses 1980;6:785-800.

10. Horrobin DF. The roles of essential fatty acids in the development of diabetic neuropathy and other com- plications of diabetes mellitus. Prostaglandins Leukot Essent Fatty Acids 1988;31:181-97.

11. Boberg M, Vessby B, Selinus I. Effects of dietary supplementation with n-6 and n-3 long-chain polyunsaturated fatty acids on serum lipoproteins and platelet function in hypertriglyceridaemic patients. Acta Med Scand 1986;220:153-60.

12. Takahashi R, Inoue J, Ito H, Hibino H. Evening primrose oil and fish oil in non-insulin-dependentdiabetes. Prostaglandins Leukot Essent Fatty Acids 1993;49:569-71.

13. Cameron NE, Cotter MA, Robertson S. Essential fatty acid diet supplementation. Effects on peripheral nerve and skeletal muscle function and capillarization in streptozocin-induced diabetic rats. Diabetes 1991;40:532-9.

14. Jamal GA. The use of gamma linolenic acid in the prevention and treatment of diabetic neuropathy. Diabet Med 1994;11:145-9.

15. Jamal GA, Carmichael H. The effect of gammalinolenic acid on human diabetic peripheral neuropathy: a double-blind placebo-controlled trial. Diabet Med 1990;7:319-23.

16. Keen H, Payan J, Allawi J, et al. Treatment of diabetic neuropathy with gamma-linolenic acid. Diabetes Care 1993;16:8-15.

17. Purewal TS, Evans PMS, Havard F, O'Hare JP. Lack of effect of evening primrose oil on autonomic function tests after 12 months of treatment. Diabetologia 1997;40(Suppl 1):A556.

18. Rosenstock J. Treatment strategies and new therapeutic advances for type 2 diabetes. Diabetes Educ 2000;26:(Suppl):14-8.

19. Vaddadi KS. The use of gamma-linolenic acid and linoleic acid to differentiate between temporal lobe epilepsy and schizophrenia. Prostaglandins Med 1981;6:375-9.

20. Shuster J. Herbal remedies and seizures. Nursing 1997;27(4):75.

21. Packer L, Witt EH, Tritschler HJ. Alpha-Lipoic acid as a biological antioxidant. Free Radic Biol Med 1995;19:227-50.

22. Nagamatsu M, Nickander KK, Schmelzer JD, et al. Lipoic acid improves nerve blood flow, reduces oxidative stress, and improves distal nerve conduction in experimental diabetic neuropathy. Diabetes Care 1995;18:1160-7.

23. Low PA, Nickander KK, Tritschler HJ. The roles of oxidative stress and antioxidant treatment in experimental diabetic neuropathy. Diabetes 1997; 46(Suppl. 2):S38-S42.

24. Ziegler D, Reljanovic M, Mehnert H, Gries FA. Alpha-lipoic acid in the treatment of diabetic polyneuropathy in Germany: current evidence from clinical trials. Exp Clin Endocrinol Diabetes 1999;107: 421-30.

25. Ziegler D, Hanefeld M, Ruhnau KJ, et al. Treatment of symptomatic diabetic peripheral neuropathy with 
the antioxidant $\alpha$-lipoic acid. A three-week multicentre randomized controlled trial (ALADIN study). Diabetologia 1995;38:1425-33.

26. Reljanovic M, Reichel G, Rett K, et al. Treatment of diabetic polyneuropathy with antioxidant thioctic acid ( $\alpha$-lipoic acid): a two-year multi-center randomized double-blind placebo-controlled trial (ALADIN II). Alpha Lipoic Acid in Diabetic Neuropathy. Free Radic Res 1999;31:171-9.

27. Ziegler D, Hanefeld M, Ruhnau KJ, et al. Treatment of symptomatic diabetic polyneuropathy with the antioxidant alpha-lipoic acid: a 7-month multicenter randomized controlled trial (ALADIN III Study). ALADIN III Study Group. Alpha-Lipoic Acid in Diabetic Neuropathy. Diabetes Care 1999;22:1296301.

28. Ruhnau KJ, Meissner HP, Finn JR, et al. Effects of 3 -week oral treatment with the antioxidant thioctic acid (alpha-lipoic acid) in symptomatic diabetic polyneuropathy. Diabet Med 1999;16:1040-3.

29. Young MJ, Boulton AJ, MacLead AF, Williams DR, Sonksen, PH. A multicenter study of the prevalence of diabetic peripheral neuropathy in the United Kingdom hospital clinic population. Diabetologia 1993;36:150-4.

30. Zhang WY, Po LW. The effectiveness of topically applied capsaicin. A meta-analysis. Eur J Clin Pharmacol 1994;46:517-22.

31. Robbins WR. Clinical applications of capsaicinoids. Clin J Pain 2000;16(2 Suppl):S86-9.

32. Scheffler NM, Sheitel PL, Lipton MN. Treatment of painful diabetic neuropathy with capsaicin 0.075\%. J Am Podiatr Med Assoc 1991;81(6): 288-93.

33. Markovits E, Gilhar A. Capsaicin-an effective topical treatment in pain. Int J Dermatol 1997;36: 401-4.

34. Tandan R, Lewis GA, Badger GB, Fries TJ. Topical capsaicin in painful diabetic neuropathy. Effect on sensory function. Diabetes Care 1992;15:15-8.

35. Biesbroeck R, Bril V, Hollander P, et al. A doubleblind comparison of topical capsaicin and oral amitriptyline in painful diabetic neuropathy. Adv Ther 1995;12:111-20.

36. Chad DA, Aronin N, Lundstrom R, et al. Does capsaicin relieve the pain of diabetic neuropathy? Pain 1990;42:387-8.

37. Treatment of painful diabetic neuropathy with topical capsaicin—a multicentre, double-blind, vehiclecontrolled study. The Capsaicin Study Group. Arch Intern Med 1991;151:2225-9.

38. Tandan R, Lewis GA, Krusinski PB, Badger GB, Fries TJ. Topical capsaicin in painful diabetic neu- ropathy. Controlled study with long-term follow-up. Diabetes Care 1992;15:8-14.

39. Low PA, Opfer-Gehrking TL, Dyck PJ, Litchy WJ, O'Brien PC. Double-blind, placebo-controlled study of the application of capsaicin cream in chronic distal painful polyneuropathy. Pain 1995;62:163-8.

40. Quatraro A, Roca P, Donzella C, Acampora R, Marfella R, Giugliano D. Acetyl-L-carnitine for symptomatic diabetic neuropathy. Diabetologia 1995;38:123.

41. Stevens M, Lattimer SA, Feldman E. Protective effects of acetyl-L-carnitine on ketogenesis and sciatic nerve function in the streptozotocin diabetic rat. Diabetes 1994;43(Suppl 1):17A.

42. Merry AC, Kamijo M, Lattimer SA, Ristic H, Sima AA. Long-term prevention and intervention effects of acetyl-L-carnitine on diabetic neuropathy. Diabetes 1994;43(Suppl. 1):108A.

43. Lowitt S, Malone JI, Salem AF, Korthals J, Benford S. Acetyl-L-carnitine corrects the altered peripheral nerve function of experimental diabetes. Metabolism 1995;44:677-80.

44. Abbott CA, Vileikyte L, Williamson S, Carrington AL, Boulton AJM, ALCAR Foot Ulcer Study Group. Effect of treatment with acetyl-L-carnitine on diabetic foot ulceration in patients with peripheral neuropathy: a 1 year prospective multi-centre study. Diabetologia 1997;40(Suppl. 1):A556.

45. McCann YJ, Davis RE. Serum pyridoxal concentrations in patients with diabetic neuropathy. Aust NZ J Med 1978;8:259-61.

46. Carlson HB, Anthony EM, Russell WF, Middlebrook G. Prophylaxis of isoniazid neuropathy with pyridoxine. N Engl J Med 1956;255:188.

47. Jones CL, Gonzalez V. Pyridoxine deficiency: a new factor in diabetic neuropathy. J Am Podiatry Assoc 1978;68:646-53.

48. Cohen KL, Gorecki GA, Silverstein SB, Ebersole JS, Solomon LR. Effect of pyridoxine (vitamin B6) on diabetic patients with peripheral neuropathy. J Am Podiatry Assoc 1984;74:394-7.

49. Levin ER, Hanscom TA, Fisher M, et al. The influence of pyridoxine in diabetic peripheral neuropathy. Diabetes Care 1981;4:606-9.

50. McCann VJ, Davis RE. Pyridoxine and diabetic neuropathy: a double-blind controlled study. Diabetes Care 1983;6:102-3.

51. Tutuncu NB, Bayraktar M, Varli K. Reversal of defective nerve conduction with vitamin $\mathrm{E}$ supplementation in type 2 diabetes: a preliminary study. Diabetes Care 1998;11:1915-8.

52. Sindrup SH, Madsen C, Bach FW, Gram LF, Jensen TS. St. John's wort has no effect on pain in polyneuropathy. Pain 2001;91:361-5. 